\title{
On Forgetting Phenomenon in English Vocabulary Memorizing of Vocational College Students in Leshan City, Sichuan, China
}

\author{
ZHOU Ye \\ Leshan Normal University, Leshan, China
}

\begin{abstract}
Memory plays a vital role in the process of English vocabulary memorizing. Nevertheless, vocational college students often find it hard to retain their memories over long periods of time despite having tried many ways to enhance their memories. In fact, English vocabulary memorizing has become a serious problem for most vocational college students in China for lack of efficient methods and consciousness of overcoming forgetting phenomenon. Under the guidance of psychological experiments and theories of forgetting, this paper presents an analysis of the factors worsening forgetting phenomenon in English vocabulary memorizing from the aspects of both students and teachers, based on a survey carried out in Leshan Vocational and Technical College. Finally, this paper puts forward some solutions aiming to decrease the students' English vocabulary forgetting rate and improve their efficiency of memorizing English vocabulary.
\end{abstract}

Keywords: forgetting phenomenon, English vocabulary memorizing, vocational college students

\section{Memory}

According to Wikipedia, "In psychology, memory is the process in which information is encoded, stored, and retrieved". Further, memory is divided into three basic stages: memorization, retention, recognition and recall.

Basically, memorization, referring to encoding of information, is the first stage. It can be further divided into intentional memorization, unintentional memorization, meaningful memorization, as well as mechanical memorization. According to the previous study, vocational college students in China often use intentional and mechanical memorization methods to memorize English vocabulary.

The second memory stage is retention, which is not only a further enhancing of memorization, but also an important guarantee of the third stage. But this stage is a dynamic change process as time goes by, and the change is forgetting. According to YAN Guo-cai (1998), "In fact, memory retention and forgetting are complementary to each other, and sometimes forgetting is not a bad thing. The dialectical relationship between them is that the less you can keep in mind, the more you will forget" (p. 70).

Recognition and recall is the third memory stage, which is a retrieval process of information that has been stored according to the view of information processing theory. But sometimes, retrieval of information may be effortless for different reasons. According to XU Jian-qi (2013), "When the content of memory cannot or

ZHOU Ye, lecturer, master, School of Foreign Language, Leshan Normal University. 
incorrectly be recognized or recalled, forgetting comes into being, which is a universal psychological phenomenon" (p. 74).

\section{Psychological Study of Forgetting Phenomenon}

\section{Features of Forgetting}

In 1885, the German psychologist Hermann Ebbinghaus implemented one of the earliest experiments of the mechanisms of forgetting. Taking himself as the study object, he memorized a series of nonsense materials, and then recorded his own capacity of memory retention after a variety of given time period. After the analysis, he found that forgetting phenomenon occurs right after the learning, and he also found that the forgetting process shows a beginning rapidly and then stabilizing tendency. Ebbinghaus developed a forgetting curve according to his findings, on which he based two conclusions. The first conclusion is that much of what we forget is lost immediately after it is originally learned. And the second is that the amount of forgetting eventually stabilizes. (Ebbinghaus, 1885)

After Ebbinghaus, a lot of similar experiments further discussed the features of forgetting and found that memory retention would not only be influenced by time factor but also be affected by the following four aspects: the type and amount of memory material, the degree of learning, serial position of memory material and learner's attitude (XU, 2013, pp. 74-75).

\section{Theories of Forgetting}

According to the study of psychology, the most popular theories are Decay Theory and Interference Theory. The Decay Theory and the Interference Theory are two suggested reasons why people forget.

The term "Decay Theory" was first coined by Edward Thorndike in his book The Psychology of Learning in 1914. It proposes that memory fades over time. Information is therefore less available for later retrieval as time passes and memory, as well as memory strength, wears away. It also states when something new is learned, a neurochemical, physical "memory trace" is formed in the brain and as time passes this trace tends to decay, unless it is occasionally used (Oberauer \& Lewandowsky, 2008). In other words, the reason why we eventually forget something is that the memory of it fades with time.

Interference Theory starts from John A. Bergström, a German psychologist in 1892. It states that forgetting results from interference for other stimulus between learning and recalling. There are two main kinds of interference: proactive interference and retroactive interference. Proactive interference means that the prior learning material makes it difficult to recognize and recall the newer learning material. On the contrary, retroactive interference refers that the newer learning material makes it hard to maintain or recall the prior learning material. As compared to proactive interference, retroactive interference may have larger effects because of the fact that there is not only competition involved, but also unlearning (Melton \& Lackum, 1941).

\section{Factors Worsening Forgetting Phenomenon in English Vocabulary Memorizing}

According to above-mentioned features and theories, the author carries out a survey among 250 students in Leshan Vocational and Technical College, and finds some major factors that worsen forgetting phenomenon in English vocabulary memorizing from the aspects of both students and teachers after the analysis of the data. 


\section{Student's Lack of Effective Methods of Memorizing English Vocabulary}

According to the survey, lack of effective methods of memorizing English vocabulary is a common problem among vocational college students. Most of them would like to memorize vocabulary by rote learning, which makes them fail to achieve their vocabulary goal and tend to forget despite working very hard and memorizing these words repeatedly. Without an effective method to memorize vocabulary, it is hard for them to improve memory efficiency, and forgetting phenomenon, therefore, would be frequent.

\section{Student's Lack of Clear Goal of English Vocabulary}

Students' lack of clear goal of English vocabulary is another general problem. Most of the vocational college students attempt to remember all of the words they meet without knowing whether it is necessary. Thus they have to memorize more words than their brains can store. As a result, actually, forgetting phenomenon comes into being. If this phenomenon often occurs, they would begin to lose their interest, patience, and even be tired of memorizing English vocabulary.

\section{Student's Psychological Obstacle in English Vocabulary Learning}

Psychological obstacle in English vocabulary learning has always been difficult for students to overcome. Its main representations are "apathetic interest, restless state, self-satisfaction, lazy by nature, distractibility, and strong dependency" (YAN, 2012, p. 103). Unfortunately, the survey finds almost every student has above-mentioned psychological obstacle more or less, which will greatly affect their learning so that they have low memory efficiency. Also, the obstacle will interfere with their memory retention on a certain extent.

\section{Teacher's Lack of Teaching Cognition of English Vocabulary}

According to the survey, teacher's lack of comprehensive cognition of teaching English vocabulary is a general problem in vocational colleges. Most teachers hold that vocabulary teaching is to teach sound, spelling, and the Chinese meaning of English vocabulary, and students will master the new vocabulary in this way, thus they often put more emphasis on the denotative meaning. "Some teachers pay more attention to connotative meaning, collocations, synonyms, antonyms, hyponyms, and receptive and productive vocabulary, but often ignore words, phrases, compound words, word formation and idioms" (Zhu, 2010, p. 36). So, as the helper and guider of students, teachers must have a comprehensive cognition of vocabulary teaching in the first place, so as not to give students misleading information in vocabulary learning.

\section{Teacher's Lack of Appropriate Teaching Strategies of English Vocabulary}

The analysis of the data shows that there are three problems in English vocabulary teaching. First, most teachers lack clear goal of vocabulary teaching. In this case, the teachers fail to achieve communicative goals of vocabulary teaching while the students fail to master thee flexible use of vocabulary. Secondly, most teachers teach vocabulary out of context, and the vocabulary practice is only exam-oriented instead of communication-oriented, which makes students feel that vocabulary practice just likes mechanical memory thus gradually lose their interest. Thirdly, most teachers tend to teach all usages and example sentences in the vocabulary teaching, so that the forgetting phenomenon tends to occur in students' memorizing the vocabulary. The less we memorized, the slower we forgot (Xu, 2013, p. 74).

What is more, the Interference Theory tells us that the newer memory and our prior memory will be interfered with each other. But this is a point that teachers tend to neglect. So the teachers usually ignore whether 
the new words are similar to the old ones in pronunciation, spelling, or meaning, whether there are some differences between them, and whether there are some relations between the new and old teaching materials. Also the teachers seldom make a comparison of two words to be homographs, homophones or complete homonyms. Therefore, students often get confused and forgetting phenomenon is getting worse.

\section{Teacher's Neglect of Students' Learning Level}

In English vocabulary teaching, most teachers often ignore students' learning level when they prepare their teaching plans. Most of them hold that the best way for students to enlarge vocabulary is to continuously memorize new words. But the author does not think so. XU jian-qi (2013, p. 74) pointed out that memory retention would be affected by the type and amount of memory material. The less we memorized, the slower we forgot. So, excessively memorizing vocabulary in a period of time goes beyond students' learning level, bound to cause negative influence. In addition, most vocabulary teaching materials in vocational colleges are out of date, which would affect students' memory because learners' attitude is another key factor for memory retention (XU, 2013, p. 75). To sum up, teacher's neglect of students' learning level will discourage students from mastering the vocabulary, so the forgetting phenomenon will be even more serious.

\section{Solutions to the Problem of Forgetting in English Vocabulary Memorizing}

In this part, some solutions are presented aiming to help vocational college students to decrease their vocabulary forgetting rate and improve their memory efficiency.

\section{Mastering Scientific Methods of Memorizing Vocabulary}

Scientific methods of memorizing vocabulary will effectively decrease students' forgetting rate. Popular methods include creating associations, using mnemonic devices, understanding, chunking, and elaborating.

Creating associations is a good method to memorize vocabulary. The author supports the idea that "frequent association can make easy memory and long retention" (Y. X. CHEN \& J. Z. CHEN, 2013, p. 43). Whether you are learning vocabulary in your native language or a foreign language, associations can help you memorize new words. Absurd, vivid, or ridiculous associations are most likely to help you retain your new vocabulary.

Using mnemonic devices is another effective method. The most popular mnemonic devices consist of "acronym, keyword method, connection method, homophonic method, and loci method" (Bohlin, Durwin, \& Reese-Weber, 2012, p. 161). For instance, students can use acronym "ROY G BIV" to memorize the colors of rainbow. For another example, students can memorize such words as dining room, living room, bathroom, etc., by imaging the specific positions in their house.

Understanding is a method on the premise of mechanical memorization. It requires that students must completely understand the vocabulary instead of simply knowing the literal meanings. The most traditional methods are mechanical memorization and intentional memorization. Besides, teachers properly using unintentional memorization may receive an unexpected result in vocabulary teaching. In fact, correctly and appropriately using the above-mentioned four methods of vocabulary memorizing can help students to retain their memory over long periods of time and reduce the forgetting phenomenon.

Chunking is a method that functions by dividing scattered vocabulary into meaningful groups, making vocabulary more meaningful and manageable. For example, when students meet these words: horse, orange, dog, 
banana, light, pear, mouse, sofa, and table, they can memorize them by dividing them into three categories: fruit, animal, and furnishing.

Finally, "Elaborating is the extensiveness of information processing involved in encoding" (Santrock, 2005, p. 252). "It adds to the distinctiveness of memory code" (Ellis, 1987, p. 265). By this way, elaborating makes the vocabulary more meaningful by linking with more information in vocabulary memorizing. For instance, when a teacher introduces the concept of "personification" to students, they will, of course, remember it better if they can come up with vivid examples of it than they just only remember the concept itself. J. P. Guilford's findings also confirm this point that we would forget the meaningful materials slower than meaningless material (XU, 2013, p. 74).

To sum up, these methods are not completely independent, but interrelate with each other. Therefore, students are supposed to choose two or more methods in their vocabulary learning.

\section{Grasping Effective Strategies of Memorizing Vocabulary}

Actually, grasping effective strategies of memorizing vocabulary will help students to save a lot of time in vocabulary memory with high efficiency.

Finding out the optimal memory time. Scientific study finds that man has four optimal memory time periods in one day. The first period is 6-7 a.m. when the brain has just finished yesterday's information encoding, and the memory efficiency is very high for there is no new memory material to interfere with brain. Then, the second period is $8-10$ a.m.. The third period is $6-8$ p.m.. And the last period is around 10 p.m.. It is admitted that different people may have different optimal time periods. So, everyone should make best use of optimal time based on his/her own conditions, so as to memorize English words with high efficiency.

Working out reasonable review plan. In order to retain vocabulary memory long and firm, working out a reasonable review plan is very important. One of the most important things students must bear in mind is to take regular review so as to slow down the process of forgetting. They can make a daily plan, weekly plan, or monthly plan to review the words they have memorized based on the amount of vocabulary and their own learning level. What is more, one of Ebbinghaus's experiments found that people tend to recall the first and last items best and the middle items worst when asked to recall a list of items in any order, which is called Serial Position Effect (XU, 2013, p. 75). Therefore, the students should realize that the middle part of vocabulary items is the most needed to review.

Applying appropriately overlearning. Generally speaking, overlearning is the continued practice or study of material or a skill long after information or the skill has been mastered. W. C. F. Krueger did an experiment showed that overlearning is helpful for memory retention and the best degree of learning is around $150 \%$ (XU, 2013, p. 75). Therefore, applying appropriately overlearning will benefit students' vocabulary memory. If they were, for instance, studying vocabulary for a foreign language, they would at some point master the material. With overlearning, they continue to study mastered material so that it hopefully becomes automatic.

\section{Overcoming Psychological Obstacles}

It is acknowledged by both educators and teachers that how to overcome the psychological obstacles in English vocabulary learning has been a big problem. As a matter of fact, memorizing vocabulary is incredibly boring. Because both interest and motivation are key factors seriously affecting students' memory retention, in 
English vocabulary teaching we should add some background information and culture to motivate students' interest so as to improve their study efficiency. In vocational colleges, some students memorize vocabulary depending on their mood or feeling. They need more study pressure from the school or parents. Some students are apt to self-satisfaction. If they get a high mark in a vocabulary test, they would think memorizing vocabulary is easy, which is a wrong self-evaluation. Some students are too lazy to spend time memorizing vocabulary. They need to know the importance of memorizing vocabulary. Some students who are easily distracted by other things than study may start from a certain amount of vocabulary. And other students are always in the receptive and passive state because of strong dependency on their teachers.

However, overcoming psychological obstacles mainly depends on the students themselves. Students in vocational colleges should fully realize the necessity and importance of overcoming psychological obstacles, then foster a good learning habit, and finally take some effective measures to overcome them. Only in this way can students improve their efficiency of vocabulary learning, and can the forgetting be reduced.

\section{Improving Teacher's Strategies of Teaching English Vocabulary}

As we know, teacher's teaching strategies of vocabulary will greatly affect students' vocabulary learning. Some effective methods in vocabulary teaching are as follows.

First, learning vocabulary is laborious and tedious. It is advisable that teachers can use games to teach vocabulary, for games will provide an interesting and relaxing learning atmosphere for students, which can improve students' learning motivations and interests. "Students have the chance to use the language in a non-pressure way after learning and practicing new vocabulary. In the easy, relaxed atmosphere which is created by using games, students remember things faster and better" (GONG, 2012, pp. 113-114).

Secondly, because words are composed of affixes and roots, using affixes and roots is another good method for vocabulary teaching. For instance, knowing that affix "un-" means "not" can deepen the students' comprehension of these words. In addition, using suffixes, prefixes, and roots will help students guess the meanings of new words they meet in reading. "Using word parts can be a particularly useful strategy in reading texts. Modelling how to break words into parts may be necessary" (JIANG, 2012, p. 168).

Finally, "From the investigation, about $97 \%$ students have not used graphic organizers to memorize words" (JIANG, 2012, p. 169). Using graphic organizers is a special strategy to memorize vocabulary; in fact, it is equal to a deeply processing of vocabulary memory. This method can not only enrich students' vocabulary, but also expand teachers' direct instruction of vocabulary.

\section{Conclusion}

To sum up, the forgetting phenomenon in English vocabulary memorizing is an inevitable and common problem, which has not been taken seriously in present vocational colleges. It is caused by many factors like student's lack of clear goal of English vocabulary, students' lack of effective methods of memorizing English vocabulary, students' psychological obstacles, and teacher's lack of appropriate teaching strategies of English vocabulary, etc.

But on the other hand, although it is inevitable, it is not unsolvable. In fact, there are some effective measures to help students improve their vocabulary memory efficiency and reduce the forgetting phenomenon in their vocabulary learning. For instance, students can take advantage of the forgetting curve to work out 
reasonable review plans, they can overcome psychological obstacles in vocabulary study, and teachers can improve the strategies of teaching vocabulary, etc. If the forgetting phenomenon in vocabulary study can be reduced, students would be more passionate and interested in memorizing English vocabulary with greatly improved efficiency and promising progress in English learning.

\section{References}

Bohlin, L., Durwin, C. C., and Reese-Weber, M. (2012). Edpsych: Modules. (L. RONG et al., Trans.). Beijing: China Machine Press.

CHEN, Y. X., \& CHEN, J. Z. (2013). An easy and effective approach to English vocabulary learning. English Square (Academic Research), 10, 43.

Ebbinghaus, H. (1885/1913). Memory: A contribution to experimental psychology. New York: Teachers College, Columbia University.

Ellis, H. C. (1987). Recent developments in human memory. In V. P. Makosky (Ed.), The G. Stanley hall lecture series. Washington, DC: American Psychological Association.

GONG, T. L. (2012). Using games for vocabulary teaching and learning. Overseas English, 7, 113-114.

JIANG, C. (2012). The present situation of vocabulary teaching in high school and suggested strategies. Science \& Technology Information, 4, 168-169.

Melton, A.W., \& Lackum, W. J. von. (1941). Retroactive and proactive inhibition in retention: Evidence for a two-factor theory of retroactive inhibition. American Journal of Psychology, 54, 157-173.

Oberauer, K., \& Lewandowsky, S. (2008). Forgetting in immediate serial recall: Decay, temporal distinctiveness, or interference? [Electronic version]. Psychology Review, 115(3), 544-576.

Santrock, J. W. (2005). Educational psychology (3rd ed.). Beijing: Beijing World Publishing Corporation.

Thorndike, E. L. (1914). The psychology of learning (p. 4). N. Y.: Teachers College.

XU, J. Q. (2013). Psychology of school education. Beijing: Beijing Normal University Press.

YAN, G. C. (1998). Learning psychology. Beijing: Police Education Press.

YAN, J. S. (2012). Efficient learning strategies. Beijing: National School of Administration Press.

ZHU, X. Y. (2010). English teaching strategies: How to make effective choice and application. Shanghai: Shanghai Foreign Language Education Press. 